\title{
Nonunion of the humeral shaft successfully treated with teriparatide [rh (1-34) PTH]
}

\author{
Ángel Oteo-Álvaro ${ }^{1 \#, ~ M a r i ́ a ~ T . ~ M a r i ́ n ~}{ }^{2}$ \\ ${ }^{1}$ Fragility Fracture Treatment Unit, Hospital Universitario de Madrid, Madrid, Spain; \\ ${ }^{\#}$ Corresponding Author: angel oteo@telefonica.net \\ ${ }^{2}$ Primary Care, C. S. General Ricardos, Madrid, Spain; maite_marin@telefonica.net
}

Received 15 January 2013; revised 24 February 2013; accepted 1 March 2013

\begin{abstract}
We reported a case of atrophic nonunion after humeral shaft fracture in a patient with severe psychiatric disorders that advised against hospital admission and surgery. He was treated with teriparatide (recombinant human 1-34 parathyroid hormon) [rh (1-34) PTH] in daily subcutaneous injections. After 4 months of treatment, healing of nonunion, associated to clinical improvement and functional recovery of the patient, was observed. No other intervention was required, and no side effects attributable to the drug occurred.
\end{abstract}

Keywords: Atrophic Nonunion; Delayed Healing; Humeral Shaft Nonunions; Nonunion; Teriparatide

\section{INTRODUCTION}

Occurrence of nonunion in the humeral shaft increases morbidity and decreases functional capacity. Multiple procedures may be used to achieve healing of nonunion, including open reduction, internal or plate fixation, or use of autologous bone grafting, allograft, or demineralized bone matrix. Adequate treatment of nonunion requires an understanding of its biomechanical and biological causes. Hypertrophic nonunions may show exuberant callus formation around the fracture site. As they are biologically active, they will heal adequately once deformities are corrected and stability is improved. Synovial nonunions, covered with cartilaginous tissue, and infected nonunions required removal of devitalized tissue and adequate stabilization. Finally, in atrophic nonunions with little or no bone callus formation osteogenic capac-

\footnotetext{
"Ángel Oteo-Álvaro was a member of Eli Lilly Spain Speakers' Bureau. María Teresa Marín doesn't have conflict of interest. Author, their immediate family, and any research foundation with which they are affiliated did not receive any financial payments or other benefits from any commercial entity related to the subject of this article. Author states that this clinical case report did not receive outside funding or grants.
}

ity must be restored by bone grafting [1]. It is in this type of nonunion where pharmacological agents with osteogenic capacity could have an attractive role in the future.

\section{METHODS}

The patient was a 39-year-old Caucasian male, smoker of 10 - 15 cigarettes daily, diagnosed with paranoid schizophrenia and depressive syndrome that was being treated with olanzapine $5 \mathrm{mg}$ /day, lormetazepam $1 \mathrm{mg}$ /day, clorazepate dipotassium $45 \mathrm{mg} /$ day in 3 doses, and lorazepam $3 \mathrm{mg} /$ day in 3 doses. He had cocaine and alcohol addiction problems and was voluntarily participating in a methadone treatment program. The patient sustained a multifragmented fracture of the right humerus $[\mathrm{AO} / \mathrm{As}-$ sociation for the Study of Internal Fixation (ASIF) type C] (Figure 1) after an accidental fall at home. There were no associated neurovascular symptoms.

Upon admission, normal results were reported for the following laboratory parameters, among others: total alkaline phosphatase and its bone fraction, liver function tests, including negative serologic tests for hepatitis $\mathrm{B}, \mathrm{C}$ and HIV, serum creatinine, ionic calcium, erythrocyte sedimentation rate, $\mathrm{C}$ reactive protein, 25 -hydroxy-vitamin $\mathrm{D}$, parathyroid hormone, prolactin, testosterone and 24-hour urinary calcium. Dual energy X-ray absorptiometry (DXA scan) revealed normal values (lumbar spine DXA scan T score- 0,9 ; total hip T score- 0,8 ; femoral T score- 0,9 ).

Based on the clinical condition and the patient's own decision, treatment consisted of immobilization with plaster, followed by a functional brace. At 7 months, patient reported pain and mobility in the fracture site, and Xrays showed no signs of union (Figure 2). Patient refused use of surgery, but accepted an empirical treatment with teriparatide [rh (1-34) PTH] $20 \mu \mathrm{g}$ as a subcutaneous daily injection.

\section{RESULTS}

At 4 months of treatment, X-ray images showed bone union (Figure 3). This was associated to disappearance 


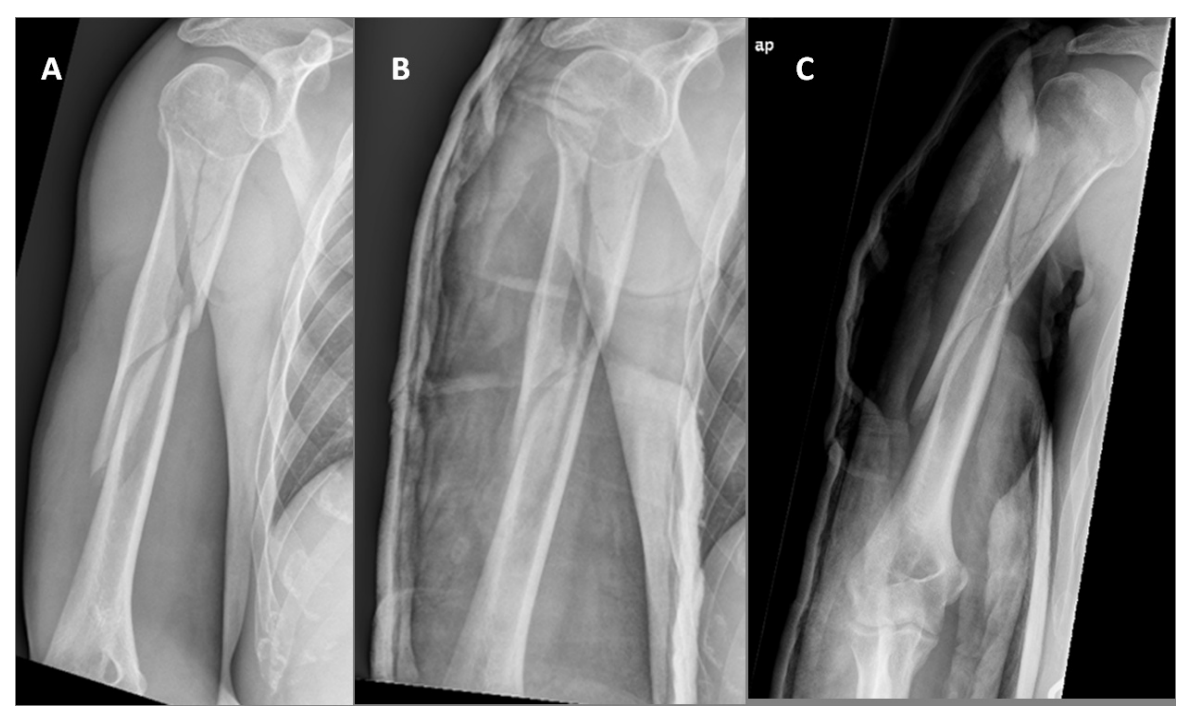

Figure 1. Humeral shaft fracture, AO/Association for the Study of Internal Fixation (ASIF) type $\mathrm{C}$, with a $10^{\circ}$ angulation and no apparent shortening.

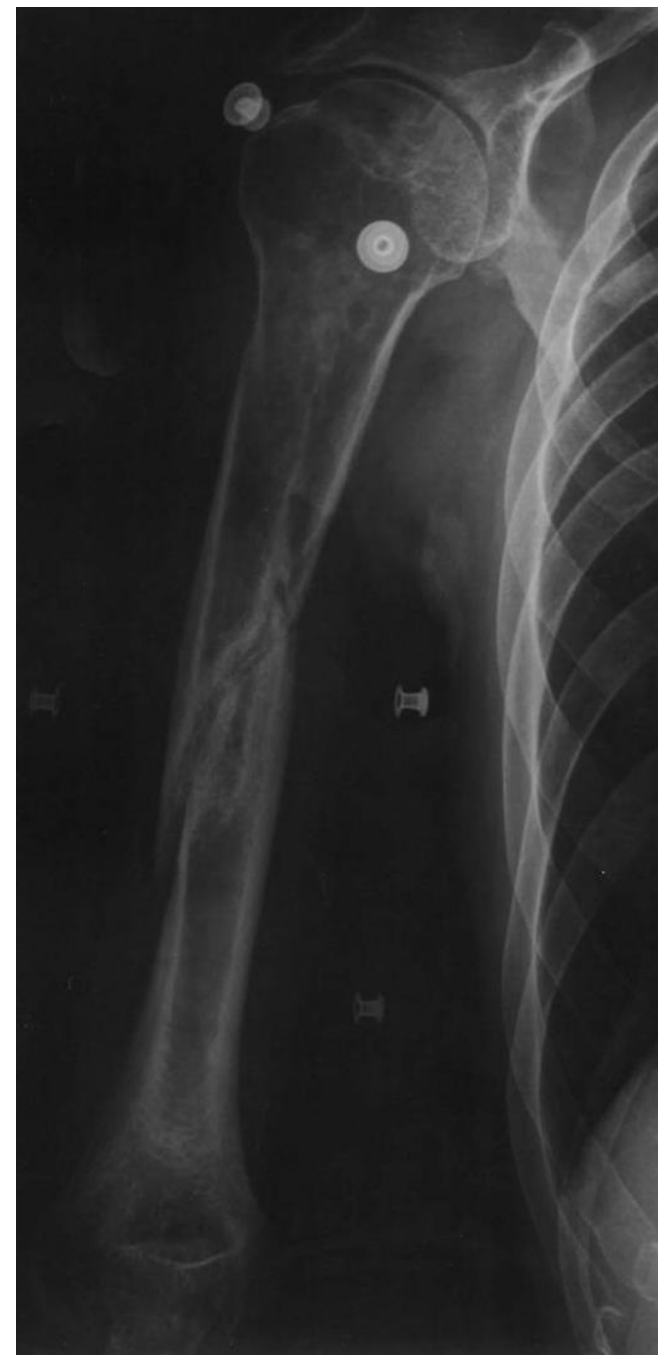

Figure 2. X-ray image 7 months after fracture with no signs of union and osteopenia/bone loss.

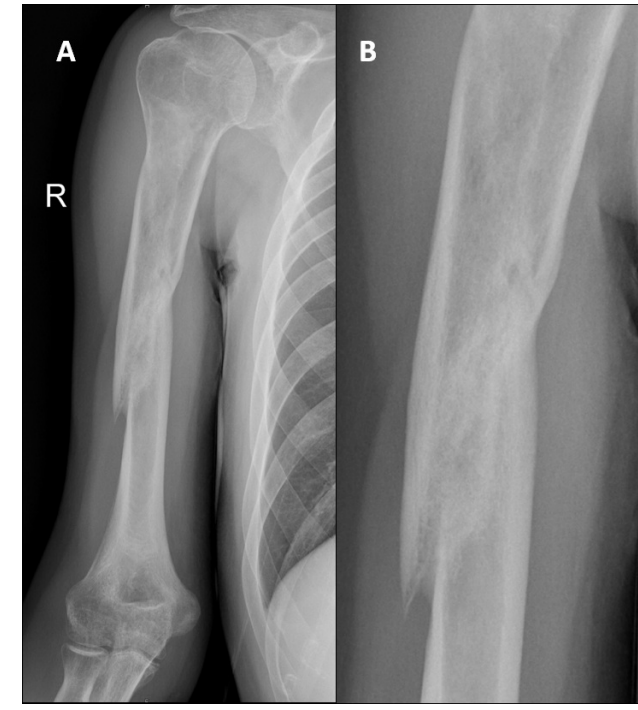

Figure 3. X-ray image after 4 months of treatment with teriparatide. Union is seen.

of pain and complete functional recovery which allowed the patient to return to his usual activities (Figure 4). Results of laboratory tests performed during treatment were normal, showing no complication attributable to the drug. No side effects attributable to the drug were observed during treatment and subsequent laboratory tests continued to be normal.

In accordance with Spanish law regarding data protection (Organic Law 15/1999), the patient authorized his clinical data to be published in a scientific journal and signed inform consent.

\section{DISCUSSION}

Uncomplicated humeral shaft fractures may be ade- 


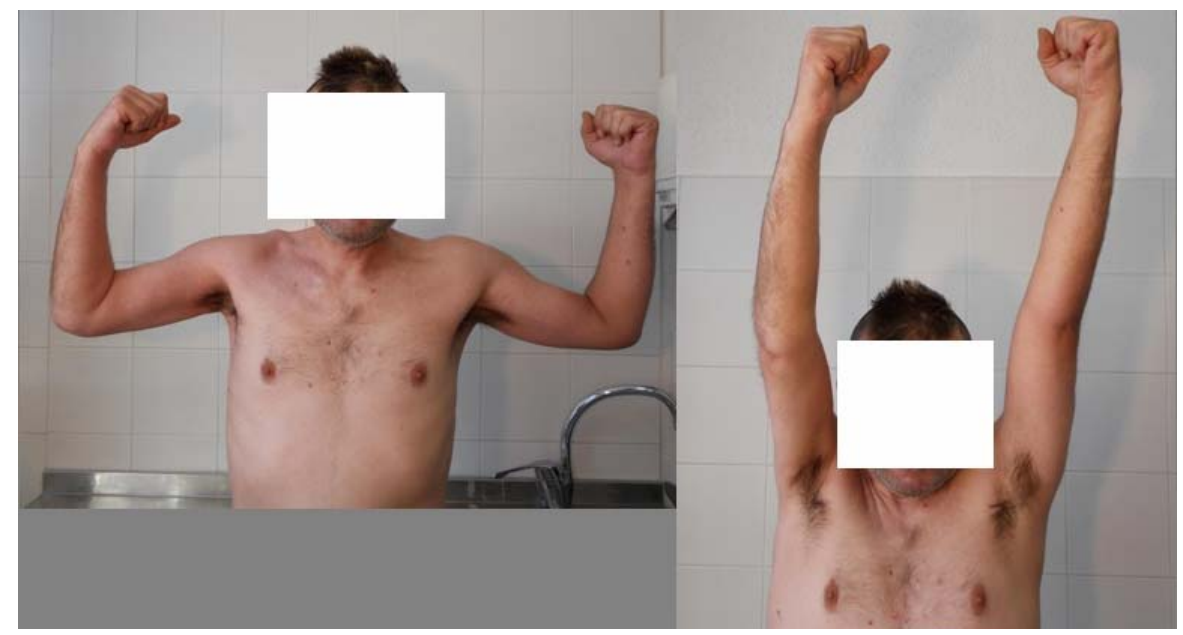

Figure 4. Full functional recovery.

quately treated with non-surgical procedures [2-7]. In certain situations such as open fractures, fractures associated to vascular and/or nerve lesions, and bilateral or multiple fractures, there is a clear indication for surgery consisting of osteosynthesis with either a plate or an intramedullary nail $[7,8]$. However there are a number of clinical situations where treatment selection is difficult because special attention should be paid to characteristics of the patients, as occurs when these are poorly cooperative $[9,10]$.

This patient, based on his severe psychiatric disorders advising against hospital admission and his own will, was place a functional brace despite the fact that the fracture affected the proximal third of the dyaphysis with a long oblique line, and risk of delayed union was therefore high [11].

With conservative treatment, union of humeral shaft fractures occurs in approximately 16 weeks [12]. Incidence of humeral shaft nonunion ranges from $0 \%$ and $8 \%$ after conservative treatment of these fractures and from $0 \%$ and $13 \%$ after surgical treatment. Atrophic nonunions are most common [13]. A number of risk factors have been reported to be associated to nonunion of humeral fractures [13-16] (Table 1), including cigarette smoking. According to data from animal models, certain prostaglandins (E and $\mathrm{F} 2 \alpha)$ are involved in the early stages of the union process [17]. Inhibition of cyclooxygenase (COX) activity by nonselective nonsteroidal antiinflammatory drugs (NSAIDs) and selective COX2 inhibitors decreases levels of such prostaglandins $[17,18]$. It appears that this inhibition would be related to the time of exposure to the drug and that these negative effects would be reversible after short treatment periods [19]. The role of NSAIDs in delaying the union process in humans is currently controversial, and there are reports advising against their use in close temporal proximity to a fracture [20-22].
Seven months after the fracture, the patient had clinical symptoms and radiographic signs of nonunion, and off-label treatment with teriparatide was therefore started. Teriparatide is approved by the Food and Drug Administration and the European Medicines Agency to treat osteoporosis in post-menopausal women and men at high risk of fracture, and in glucocorticoid-induced osteoporosis. Teriparatide stimulates bone formation, improving some macro and microarchitectural characteristic of bone [23], and it appears to have a potential to accelerate fracture callus formation and remodeling during bone repair. It may accelerate bone healing through stimulation of the Wnt path system, among others [24]. This effect was shown in a clinical trial conducted in distal radial fractures in osteoporotic postmenopausal women. Fracture healing was achieved 2 weeks earlier in the group treated with teriparatide $20 \mu \mathrm{g}$ daily, the approved dose for the treatment of osteoporosis, as compared to the placebo group [25]. There are also clinical reports of treatment of different fracture models [26,27] and cases of delayed union and nonunion [28-30]. We recently reported a clinical case of healing of atrophic nonunion of the humeral shaft following osteosynthesis with flexible intramedullary nailing in which 3 months of teriparatide treatment achieved full functional recovery [31].

In the reported case, after 4 months of treatment with teriparatide and with no other intervention that could influence the final clinical outcome, was related with a radiographic image of union associated with full functional recovery, which - in author's opinion - was causally related to the treatment administered.

Systemic administration of drugs to accelerate fracture union is an attractive option, which becomes particularly relevant in situations in which a high surgical risk exists. The clinical trial conducted by Aspenberg et al. [25] in distal radial fractures in women with osteoporosis support this accelerating effect of union of teriparatide. 
Table 1. Risk factors related with nonunion in humeral fractures.

Healy et al. 1987 (12). Retrospective review of 26 patients with nonunions of the humeral shaft.

Green et al. 2005 (13). Retrospective study with 28 patients with delayed union or nonunion of the midshaft humerus fracture.

Ring et al. 2007 (15). Retrospective study with 32 patients with nonunion after functional brace treatment of diaphyseal humerus fractures.

Decomas et al. 2010 (16). Retrospective study with 19 patients with humeral diaphyseal fractures under treatment with functional brace.

Use of teriparatide for the treatment of nonunion, particularly atrophic nonunion, is based on its osteogenic effect and has been demonstrated in case series. In the author's opinion and based on currently available data, teriparatide could be an excellent therapeutic option, alone or combined with other interventions, to achieve healing of nonunion, particularly when an increased surgical risk exists due to fracture location or clinical characteristics of the patient. However, future clinical trials will offer the possibility to obtain data that will make the registration as an accelerator for fracture healing possible.

\section{ACKNOWLEDGEMENTS}

The author thanks Dr. Fernando Marín for his good advice when evaluating these results.

\section{REFERENCES}

[1] Bosch, U., Skutek, M., Kasperczyk, W.J. and Tscherne, H. (1999) Nonunion of the humeral diaphysis-Operative and non-operative treatment. Der Chirurg, 70, 1202-1208. doi:10.1007/s001040050771

[2] Charnley, J. (1961) The closed treatment of common fractures. Williams \& Wilkins, Baltimore.

[3] Holm, C.L. (1970) Management of the humeral shaft fractures. Fundamental nonoperative technics. Clinical Orthopaedics and Related Research, 71, 132-139.

[4] Mast, J.W., Spiegel, P.G., Harvey, J.P. and Harrison, C. (1975) Fractures of the humeral shaft: A retrospective study of 240 adult fractures. Clinical Orthopaedics and Related Research, 12, 254-262.

[5] Sarmiento, A., Kinman, P., Galvin, E., Schmitt, R.H. and Phillips, J.G. (1977) Functional bracing of fractures of shaft of humerus. The Journal of Bone \& Joint Surgery, 59, 596-601.

[6] Balfour, G.W., Mooney, V. and Ashby, M.E. (1982) Diaphyseal fractures of the humerus treated with a readymade brace. The Journal of Bone \& Joint Surgery, 64, $11-13$.

[7] McKee, M.D. (2001) Fractures of the shaft off the hume-
Midshaft location of the fracture, transverse and short oblique fracture patterns, comminuted fractures, open fractures, infections, distraction of fracture fragments, primary open reduction, unstable surgical fixation, alcoholism, and poor patient compliance.

Unstable fractures (comminuted or short oblique $(83 \%)$, advanced age $(57 \%)$, obesity (35\%), daily tobacco use $(38 \%)$, multiple long bone fractures $(21 \%))$.

Spiral/oblique fractures that involve the mid- or proximal-third of the diaphysis.

Obesity (37\%), cigarette smoking (53\%), metabolic bone disease $(32 \%)$, cardiovascular disease $(37 \%)$, short oblique fractures $(89 \%)$, open fractures $(26 \%)$, fractures of the proximal third of the diaphysis $(68 \%)$. rus. In: Bucholz, R.W., Heckman, J.D. and Court-Brown, C.H., Eds., Rockwood and Green's Fractures in Adults, 6th Edition, Lippincott Williams \& Wilkins, Philadelphia, 1117-1159.

[8] Changulani, M., Jain, U.K. and Keswani, T. (2007) Comparison of the use of the humerus intramedullary nail and dynamic compression plate for the management of diaphyseal fractures of the humerus. A randomized controlled study. International Orthopaedics, 31, 391-395. doi:10.1007/s00264-006-0200-1

[9] Schatzker, J. (1996) Fractures of the humerus. In: Schatzker, T.M., Ed., The Rationale for Operative Fracture Care, 2nd Edition, Springer Verlag, Berlin, 83-94.

[10] Schemitsch, E.H. and Bhandari, M. (2001) Fractures of the diaphyseal humerus. In: Browner, B.D., Jupiter, J.B., Levine, A.M. and Trafton, P.G., Eds., Skeletal Trauma, 3rd Edition, WB Saunders, Toronto, 1481-1511.

[11] Rutgers, M. and Ring, D. (2006) Treatment of diaphyseal fractures of the humerus using a functional brace. Journal of Orthopaedic Trauma, 20, 597-601. doi:10.1097/01.bot.0000249423.48074.82

[12] Broadbent, M.R., Will, E. and McQueen, M.M. (2010) Prediction of outcome after humeral diapheseal fracture. Injury, 41, 572-577. doi:10.1016/j.injury.2009.09.023

[13] Healy, W., White, G.M., Mick, Ch.A., Brooker, A.F. and Weiland, A.J. (1987) Nonunion of the humeral shaft. Clinical Orthopaedics and Related Research, 219, 206213.

[14] Green, E., Lubahm, J.D. and Evans, J. (2005) Risk factors, treatment, and outcome associated with nonunion of the midshaft humerus fracture. Journal of Surgical Orthopaedic Advances, 14, 64-72.

[15] Ring, D., Chin, K., Taghinia, A.H. and Jupiter, J.B. (2007) Nonunion after functional brace treatment of diaphyseal humerus fractures. Journal of Trauma, 62, 1157-1158. doi:10.1097/01.ta.0000222719.52619.2c

[16] Decomas, A. and Kave, J. (2010) Risk factors associated with failure of treatment of humeral diaphyseal fractures after functional bracing. Journal of the Louisiana State Medical Society, 162, 33-35.

[17] Simon, A.M. and O'Connor, J.P. (2007) Dose and timedependent effects of cyclooxygenase- 2 inhibition on frac- 
ture-healing. The Journal of Bone \& Joint Surgery, 89, 500-511. doi:10.2106/JBJS.F.00127

[18] Gerstenfeld, L.C., Al-Ghawas, M., Alkhiary, Y.M., Cullinane, D.M., Krall, E.A., Fitch, J.L., Webb, E.G., Thiede, M.A. and Einhorn, T.A. (2007) Selective and nonselective cyclooxygenase-2 inhibitors and experimental fracture-healing. Reversibility of effects after short-term treatment. The Journal of Bone \& Joint Surgery, 89, 114-125. doi:10.2106/JBJS.F.00495

[19] Bhattacharyya, T., Levin, R., Vrahas, M.S. and Solomon, D.H. (2005) Nonsteroidal antiinflammatory drugs and nonunion of humeral shaft fractures. Arthritis \& Rheumatism, 53, 364-367. doi:10.1002/art.21170

[20] Daluiski, A., Ramsey, K.E., Shi, Y. and Bostrom, M.P. (2006) Cyclooxygenase-2 inhibitors in human skeletal fracture healing. Orthopedics, 29, 259-261.

[21] Giannoudis, D.A., MacDonald, S.J., Matthews, R.M., Smith, A.J., Furlong and De Boer, P. (2000) Nonunion of the femoral diaphysis. The influence of reaming and nonsteroidal anti-inflammatory drugs. The Journal of Bone \& Joint Surgery, 82-B, 655-658.

[22] Dodwell, E.R., Latorre, J.G., Parisini, E., Zwettler, E., Chandra, D., Mulpuri, K. and Snyder, B. (2010) NSAID exposure and risk of nonunion: A meta-analysis of casecontrol and cohort studies. Calcified Tissue International, 87, 193-202. doi:10.1007/s00223-010-9379-7

[23] Jiang, Y., Zhao, J.J., Mitlak, B.H., Wang, O., Genant, H.K. and Eriksen, E.F. (2003) Recombinant human parathyroid hormone (1-34) [teriparatide] improves both cortical and cancellous bone structure. Journal of Bone and Mineral Research, 18, 1932-1941. doi:10.1359/jbmr.2003.18.11.1932

[24] Bukata, S.V. (2011) Systemic administration of pharmacological agents and bone repair: What can we expect. Injury, 42, 605-608. doi:10.1016/j.injury.2011.03.061
[25] Aspenberg, P., Genant, H.K., Johansson, T., Nino, A.J., See, K., Krohn, K., García-Hernández, P.A., Recknor, C.P., Einhorn, T.A., Dalsky, G.P., Mitlak, B.H., Fierlinger, A. and Lakshmanan, M.C. (2010) Teriparatide for acceleration of fracture repair in humans: A prospective, randomized, double-blind study of 102 postmenopausal women with distal radial fractures. Journal of Bone and Mineral Research, 25, 404-414. doi:10.1359/jbmr.090731

[26] Puzas, J.E., Houck, J. and Bukata, S.V. (2006) Accelerated fracture healing. Journal of the American Academy of Orthopaedic Surgeons, 14, S145-S151.

[27] Resmini, G. and Iolascon, G. (2007) 79-year-old post-menopausal woman with humerus fracture during teriparatide treatment. Aging Clinical and Experimental Research, 19, 30-31.

[28] Bukata, S.V., Kaback, L.A., Reynolds, D.G., O'Keefe, R.J. and Rosier, R.N. (2009) 1-34 PTH at physiologic doses in humans shows promise as a helpful adjuvant in difficult to heal fractures: An observational cohort of 145 patients. The 55th Annual Meeting of the Orthopaedic Research Society, Las Vegas, 25 February 2009.

[29] Rubery, P.T. and Bukata, S.V. (2010) Teriparatide may accelerate healing in delayed unions of type III odontoid fractures: A report of 3 cases. Journal of Spinal Disorders \& Techniques, 23, 151-155. doi:10.1097/BSD.0b013e31819a8b7a

[30] Chintamaneni, S., Finzel, K. and Gruber, B.L. (2010) Successful treatment of sternal fracture nonunion with teriparatide. Osteoporosis International, 21, 1059-1063. doi:10.1007/s00198-009-1061-4

[31] Oteo-Alvaro, A. and Moreno, E. (2010) Atrophyc humeral shaft nonunion treated with teriparatide (rh PTH 1-34): A case report. Journal of Shoulder and Elbow Surgery, 19, 22-28. doi:10.1016/j.jse.2010.05.005 